\title{
Who supports affirmative action policies for women and immigrants in recruitment processes? An international survey experiment
}

Katja Möhring a \& Céline Teney ${ }^{\mathrm{b}}$

a University of Mannheim, Germany, E-mail: moehring@uni-mannheim.de

${ }^{b}$ Freie Universität Berlin, Germany, E-mail: celine.teney@fu-berlin.de

\begin{abstract}
Affirmative action policies (AAP) polarise the public debate in Western democracies as they involve favouring a candidate at the cost of others because of group membership. Against this backdrop, we ran a factorial survey experiment in Denmark, France and Germany on the introduction of a hypothetical regulation favouring women and immigrants by equal qualifications in the recruitment process for a managing position. Our data show that support for AAP is significantly larger for women than for immigrants. Moreover, support for AAP is much higher in France than in Germany and Denmark. Germans and Danes show similar low support for AAP for immigrants, while support for AAP for women is higher in Germany than Denmark. We conducted multilevel regression models to investigate the power of several attitudinal factors in explaining target group and country differences. Results show that respondents' varying level of ethnic and gender prejudice and perceived disadvantage entirely explains target group differences in support for AAP. Furthermore, differences between Germany and Denmark in support of AAP for women are explained by different levels of prejudices and perceived disadvantage, and attitudes toward state intervention. However, these attitudinal variables cannot explain why support for AAP is much higher in France.
\end{abstract}




\section{Introduction}

Identity politics have become one of the most polarising policy areas in Western democracies (Fukuyama 2018). Proponents of identity politics consider group-based rights a necessary and complementary tool to individual-based rights for redressing group-based unequal participation in various societal arenas. By contrast, opponents of identity politics argue that the allocation of particular rights to individuals because of a common group membership is likely to lead to a fragmentation of the society into subgroups defined by particular identities perceived as constitutive. Accordingly, the incorporation of such constitutive group identities in the design of policies aiming at redressing inequality is said to weaken social cohesion. Affirmative action policies (AAP) constitute one of the most contested and polarising forms of identity politics as they involve favouring a candidate at the cost of others because of his/her group membership. AAP imply that members of underrepresented groups are given preference over others in selection processes for leadership positions and/or public offices and are thus outcome-based group-based policies (Harrison et al. 2006). As AAP are often perceived as a zero-sum game, they compose an important topic of contestation between proponents and opponents of identity politics.

Investigating the determinants of support for AAP has therefore a particularly large societal relevance: it can provide empirical evidence on the mechanisms underpinning societal polarisation on a particularly contested form of identity politics, thereby helping to understand why AAP might produce unintended outcomes (de Zwart 2000). Moreover, this issue provides an interesting scientific inquiry. Support for AAP results indeed from an interplay of several attitudinal dimensions: identification with the target group, one's own level of prejudice against the target group, the perception of unequal opportunities faced by 
the target group and attitudes toward state intervention (Krysan 2000). Thus, investigating citizens' support for policies to redress categorical inequality can enable us to shed light on the interplay of key attitudinal dimensions underpinning the support of concrete and reallife context policies. This provides obvious advantages over the analysis of abstract attitudinal items on the acceptance of equality for underrepresented groups. The latter suffer from high social desirability bias, as the expression of overt forms of prejudice against underrepresented groups are no longer socially accepted (Krysan 2000). Moreover, abstract items measuring acceptance of equality, as frequently used in research, remain largely uncertain with respect to their implications for every day behaviour and policy attitudes outside the survey context.

Despite its particularly large societal and scientific relevance, research on citizens' support for AAP has been so far dominated by studies which focused on the US and attitudes of (white) Americans toward (existing or hypothetical) affirmative action programs for ethnic minorities (Harrison et al. 2006; Krysan 2000). The dominance of US studies on this issue has led to neglect for cross-national differences in support for AAP. However, recent studies pointed to large cross-national variation in overall AAP support (Barnes and Córdova 2016; Möhring and Teney 2020). Moreover, we still know very little about support of AAP for different underrepresented groups. To the best of our knowledge, previous research has exclusively investigated AAP for a single target group, with the recent exception of Scarborough et al. (2019). Therefore, we aim to fill these research gaps and to contribute more empirical evidence to a highly normative debated topic. We address the following two main research questions: (1) how can we explain variation in support for AAP for women and for immigrants ("immigrants" in the following) and (2) how can we explain this cross- 
national variation in the overall support for AAP and the differences between the two target groups?

Figure 1: Average level of support for AAP toward women and immigrants in Denmark, Germany and France

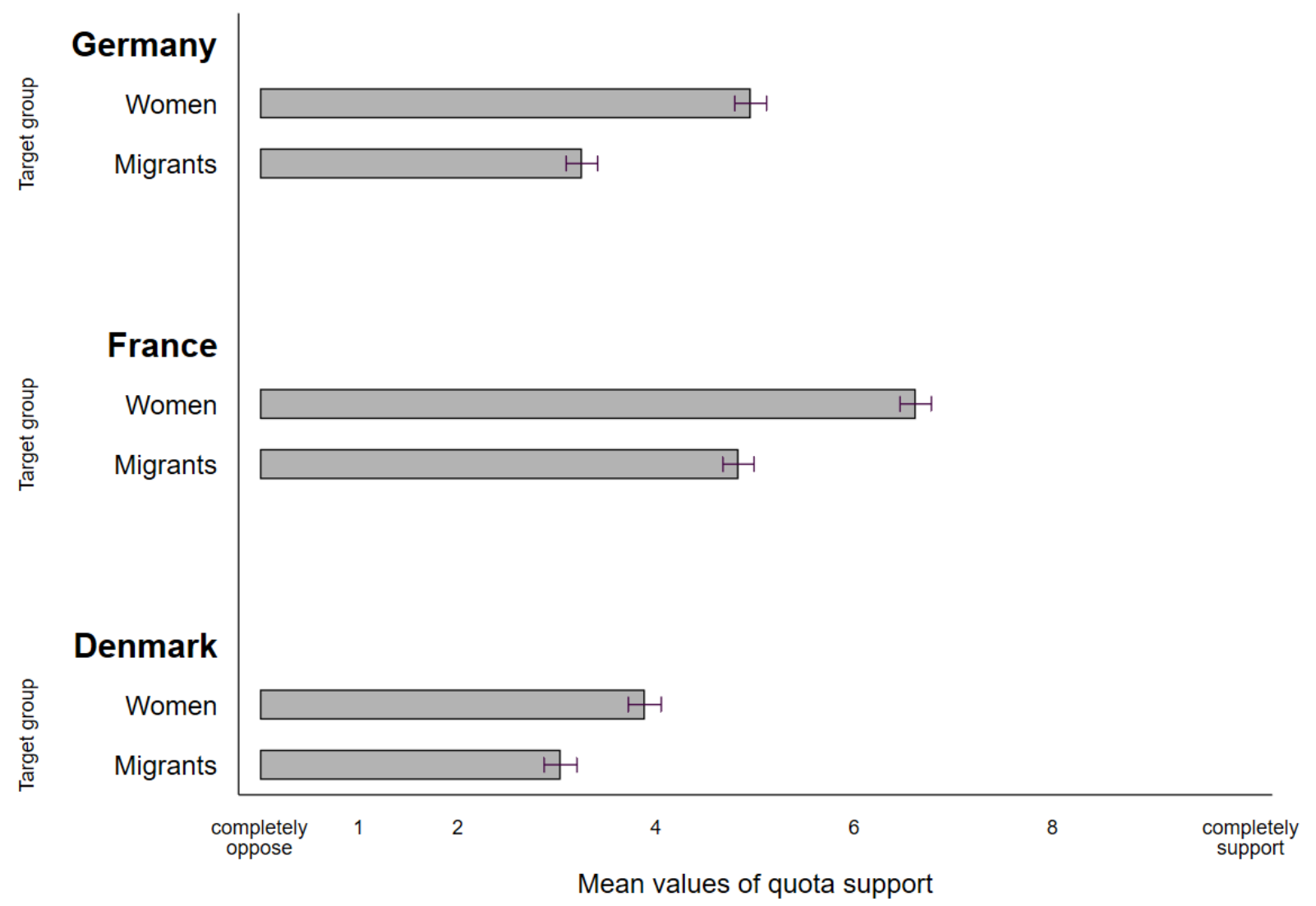

Note: The answer categories range from 0 (completely oppose) to 10 (completely support).

Based on a unique international factorial survey experiment, we aim to fill in this gap by investigating not only cross-national variation in support for AAP but also the extent to which support for AAP varies among target groups. More specifically, our survey experiment was composed of vignettes on the introduction of a hypothetical regulation favouring 
women or immigrants by equal qualifications in the recruitment process for a managing position. We conducted our vignette experiment in Denmark, France and Germany. We selected these countries because they provide contrasting average levels of support of boardroom quotas for women (Möhring and Teney 2020), of prejudice against immigrants and women and of support for state intervention (Pew Research Center 2018). Figure 1 presents the average level of support for AAP for women and immigrants in Denmark, Germany and France. As can be observed, in all countries respondents support AAP for women to a larger extent than for immigrants. Moreover, we see large cross-national variation in the overall support for AAP: support for AAP for both women and immigrants is much larger in France than in Germany and Denmark. Support for AAP for women is higher in Germany than Denmark, while Germans and Danes show a similar support for AAP for immigrants.

Four key factors have been highlighted in the literature on support for policies aimed at redressing ethnic inequality: (1) group-based interest and group identity, (2) ethnic prejudice, (3) belief about discrimination and source of inequality and (4) support for state interventionism (Dixon, Durrheim, and Thomae 2017; Sniderman, Crosby, and Howell 1999). We investigate the extent to which these four factors can explain target group and country differences in support for AAP. More precisely, we hypothesise that the differences in support for AAP targeted at women and people with an immigrant background are due to differences in the level of group identity, the level of ethnic and gender prejudice and in the level of perceived disadvantage of women and people with an immigrant background on the labour market. We develop these hypotheses by drawing on the deservingness theory underlying support for welfare benefit (van Oorschot 2000). Furthermore, we hypothesise 
that country differences in the support for AAP can be explained by country differences in the overall perception of disadvantage of women and people with immigrant background, in the overall level of ethnic and gender prejudice and in the overall support for state intervention.

\section{Explaining target group differences in support for AAP}

Existing studies investigating differences in (redistributive) solidarity between target groups consistently highlighted the significantly lower support of solidarity for immigrants than for other vulnerable groups (e.g., van Oorschot 2008). Furthermore, a recent study investigating support for diversity policies at the work place pointed to the fact that policies targeted at ethnic minorities face more opposition than policies targeted at women (Scarborough, Lambouths, and Holbrook 2019). These results reflect our descriptive findings presented in Figure 1: our respondents support AAP targeted at women to a larger extent than AAP targeted at immigrants. The exact mechanisms behind these target group differences in the support for AAP remain however an open empirical question.

To tackle this question, we draw on the deservingness theory for welfare program and redistributive solidarity (van Oorschot 2000). Deservingness can be understood as "the extent to which a subject is considered worthy or unworthy of an outcome, based upon the relative relationship between this outcome and the actions and characteristics of the subject" (Kootstra 2016, 327). Accordingly, individuals make use of five different deservingness criteria to judge whether some groups are held more deserving of welfare support than others: need, reciprocity, identity, attitudes and control. The reciprocity and need criteria do not apply to the case of support for AAP in managing positions. The reciprocity criterion 
implies that those with higher perceived contribution to society in the past, present or future are considered more deserving. The need criterion allocate more deservingness to those perceived to have greater (financial) needs (Laenen, Rossetti, and van Oorschot 2019). As AAP are neither a financial based welfare benefit nor a policy targeted at the (financially) needy, these two criteria are not applicable when judging the deservingness of women and immigrants for AAP in managing position. By contrast, the three remaining deservingness criteria provide a fruitful theoretical frame for understanding target group differences in support for AAP.

\section{Identity criterion of deservingness}

The identity criterion postulates that those who are perceived as belonging to one's own group or seen as more similar and close to the own group are judged as more deserving. This identity criterion can also be interpreted with the lens of the social identity theory: individuals who perceive that a policy will benefit members of their own group are more likely to support it. Consequently, members of the target groups are more likely to be in favour of such policies that are believed to help their own demographic group (Harrison et al. 2006). By contrast, members of the non-target group are likely to oppose affirmative action policies because they perceive members of the target groups as competitive threats for valued (but scarce) social resources, statuses and privileges (Bobo 2000, 142-43). The empirical literature on support for AAP has consistently confirmed this group interest-based explanation (e.g.,Harrison et al. 2006; Möhring, Teney, and Buss 2019; Smith and Hunt, 2020). Furthermore, recent empirical studies have pointed to the fact that members of an underrepresented group are more likely to support AAP targeted at other underrepresented 
groups than members of the majority group (i.e., white men) (e.g., Bolzendahl and Coffé 2020; Kane and Whipkey 2009; Scarborough, Lambouths, and Holbrook 2019). Therefore, as women belong to an underrepresented group, they might be more likely than men to identify and feel solidarity with other underrepresented groups, such as immigrants ${ }^{1}$ : members of an underrepresented group might not only identify with their own group but also perceive communalities with members of other underrepresented groups. Thus, the identity criterion of deservingness provides a more overarching theoretical framework for understanding group differences in support of AAP toward distinct target groups than the sole group-based interest explanation. Accordingly, we expect women to support AAP for women to a larger extent than men (Hypothesis 1a). Moreover, we also hypothesize that women will be more supportive of AAP not only targeted at women but also targeted at immigrants (Hypothesis $1 \mathrm{~b}$ ). The identity criterion of deservingness can explain differences in the support for AAP between members of underrepresented groups and the majority. However, there is also a large heterogeneity in the level of support for AAP within groups: not all majority members oppose AAP and not all members of underrepresented groups support AAP. The two further deservingness criteria provide a theoretical framework to investigate target group differences in the support for AAP among individuals.

\section{Attitude criterion of deservingness}

The attitude criterion of deservingness implies that those who are perceived as more grateful, compliant and conforming to a societies' standards are judged as more deserving

\footnotetext{
${ }^{1}$ Unfortunately, the sample design of our survey data does not allow us to investigate support for AAP among respondents of immigrant origin. Therefore, we can only assess the relevance of the identity deservingness criterion by differentiating female from male respondents.
} 
(van Oorschot 2008; 2000). For instance, Reeskens and van der Meer (2019) operationalised the behaviour of actively seeking for a job as attitudinal criterion of deservingness for unemployment aid. More broadly, earlier studies on deservingness pointed to the role of attractiveness of the target group in the evaluation of deservingness of the particular target group: we will judge a person or social group we like as more deserving than a disliked person or group (Feather 1999). We can apply this attitudinal criterion to the specific case of AAP by making the following assumption: underrepresented groups will be considered as non-deserving (1) if they are perceived as not conforming to the standards for holding a managing position or, more generally, (2) if they are disliked. Attitudinal criteria of deservingness that might apply to the case of support for AAP can encompass various negative stereotypes related to the particular underrepresented group in general or in the context of labour market for managing positions. We operationalize the evaluation of not conforming to the necessary standards for holding a management position in two ways: 1) evaluation of the underrepresented group as an economic or cultural threat and 2) evaluation of the underrepresented group as not possessing the necessary competencies and qualities for holding a management position. Holding such negative stereotypes and forms of prejudice are likely to be associated with a stronger opposition to AAP for the respective target group. Indeed, ethnic and racial prejudice are significantly related to lower support for informal solidarity toward immigrants (van Oorschot 2006), for welfare programs targeted at ethnic minorities (Harell, Soroka, and Iyengar 2016), and even reduces support for other welfare benefits (e.g., for a universal basic income, Bay and Pedersen, 2006). Overall, individuals in Western democracies show higher levels of negative stereotypes and prejudice against immigrants than against women. The varying levels of negative 
stereotypes and prejudice against women and persons of immigrant origin are therefore expected to explain the larger opposition to AAP in the case of persons of immigrant origin (Hypothesis 2): as persons of immigrant origin suffer from higher level of negative stereotypes and prejudice, they will be considered as less deserving than women. This would, in turn, explain why the overall support for AAP is higher for women as target group.

\section{Control criterion of deservingness}

Lastly, the control criterion of deservingness postulates that those perceived to have little or no personal control for getting in or out of their situation are judged as more deserving of welfare benefit. Translating the control criterion of deservingness to our case is straightforward: if members of the target group are perceived as facing a disadvantage on the labour market, they will be considered as more deserving of AAP. Indeed, as AAP for a managing position aims to redress inequality faced by underrepresented groups on the labour market, the belief that members of underrepresented groups are not disadvantaged on the labour market would imply that AAP are not necessary. This, in turn, would lead to a higher opposition to AAP. The perception that group members are unfairly treated or structurally disadvantaged is indeed a strong determinant of support for AAP for ethnic minorities (Harrison et al. 2006; Krysan 2000) and for diversity policies on the labour market for women and ethnic minorities (Scarborough, Lambouths, and Holbrook 2019). Here again, we hypothesise that target group differences in support for AAP are due to varying levels of perceived disadvantage of women and immigrants on the labour market (Hypothesis 3). 
To sum up, we expect to be able to explain differences in the support for AAP targeted at women and persons of immigrant origin by accounting for the identity, attitude and control criteria of deservingness. Thus, we assume that the target differences in the level of support for AAP is due to differences (1) in the perception of the target group as being similar to oneself (Hypotheses 1a and 1b); (2) in the level of negative stereotypes and prejudice against the target groups (Hypothesis 2); and (3) in the perception of disadvantages of the target groups on the labour market (Hypothesis 3).

\section{Explaining cross-national differences in support for AAP}

A previous study on differences in public support for the introduction of a gender boardroom quota across European countries pointed to large between-country variations (Möhring and Teney 2020). Accordingly, public support for a gender quota for company boards was higher in France, followed by Germany and then Denmark - despite all three countries exhibit similar shares of women in supervisory positions (Dämmrich and Blossfeld_2017). Figure 1 points also to a large variation in the overall support of AAP between our French, German and Danish respondents. We suggest two factors that can explain this country-level variation. First, the overall level of stereotype and prejudice against women and ethnic minorities and the overall perception of disadvantage faced by women and immigrants might vary across our sampled countries. Such cross-national variation in the overall level of prejudice and perception of disadvantage of underrepresented groups is expected to explain the country differences in support for AAP (Hypothesis 4). International survey data point indeed to considerable variation in the overall level of prejudice against ethnic minorities and women. In a recent PEW survey (Pew Research Center 2018), the proportion 
of respondents who think that immigrants make the national economy stronger because of their work and talent was much higher in Denmark and Germany (both 66\%) than in France (54\%). By contrast, Germans seem to endorse much more traditional gender roles than French people and Danes: while 68\% of Danish and 63\% of French respondents agree that it is good for family life when women have full-time jobs, only $43 \%$ of Germans do so (Pew Research Center 2018).

Second, support for AAP are not only derived from the personal level of stereotype and prejudice and the perceived disadvantage faced by underrepresented groups but also from the acceptance of a strong state intervention in the economy. Sniderman et al. (1999) even argued that prejudice is of secondary importance compared to opposition to welfare in explaining opposition to AAP. If the overall level of support for state intervention in the economy differs across our countries, this could also provide an explanation for the varying level of support for AAP between Germany, Denmark and France. A recent PEW survey points indeed to significant cross-national variation in the overall acceptance of state intervention among our sampled countries: French and Danish respondents agree to a much larger extent than Germans that it is the government's responsibility to ensure a decent standard of living for all (Pew Research Center 2018). Therefore, we hypothesise that country differences in support for AAP can be partly explained by varying levels of support for state intervention in the economy (Hypothesis 5). 


\section{Data and methods}

Data

In order to assess support for AAP for women and immigrants, we developed vignettes on a hypothetical AAP regulation. These vignettes were varying in four dimensions and were formulated as follow:

„[Women/people with a migration background] are [highly underrepresented /underrepresented] in the [private/public sector] in [country]. An independent commission suggests therefore the following regulation: employers should be legally forced to favour [women/people with an immigrant background] in the hiring process for [top/middle/low] management positions by equal qualifications. To which extent do you support or oppose this regulation?"

Respondents were asked to answer with an 11-point Likert scale ranging from 0 (completely oppose) to 10 (completely support), which constitutes our dependent variable. In this contribution, we will investigate exclusively the variation in support for AAP depending on the AAP target groups (i.e., women and persons with an immigration background). However, the vignettes contained three further dimensions besides the AAP target groups: (1) the level of segregation faced by the target group (i.e., whether the target group is underrepresented or highly underrepresented); (2) the sector of activity (i.e., private vs public) and (3) the management level of the position targeted by the regulation (i.e., top, middle or low management positions). With the exception of the target group dimension, support for the AAP regulation did not vary significantly along the levels of the three other dimensions, which is remarkable. Thus, when evaluating an AAP regulation, respondents only make use 
of the piece of information on the target group and ignore the other information describing the context of the AAP regulation. These results clearly point to the relevance of investigating variation in the support for AAP along target groups. We used a full factorial design for drawing a random sample of vignettes from the entire vignette universe considering all possible combinations of the dimensions' levels. Each respondent was randomly assigned to four versions of the vignette.

The survey experiment data were collected in September 2018 among a random sample of participants of an online panel by YouGov in Germany, France and Denmark. We selected these countries for two reasons. First, as North-Western European countries, they show a similar immigration history: a large low-skilled immigration wave of so-called guest workers coming from mainly Muslim-majoritarian countries in the 1960s and 1970s (Koopmans 2013), followed by (1) a diversification in the countries of origin and in the educational levels of immigrants; and (2) an increase in intra-EU migration (King 2002). Second, they provide contrasting contexts regarding both the structural integration of women and immigrant minorities and the target policies for their structural integration. Policies for achieving a gender balance in economic power differ in the selected countries: France introduced a gender boardroom quota already in 2011, Germany in 2016, while such a quota doesn't exist in Denmark. In a similar vein, women's economic power (measured with the share of board members in largest quoted companies, supervisory board or board of directors and with the share of board members of central bank) is much higher in France (82.9 points out of 100) than in Denmark (56.5) and in Germany (49.7) (EIGE 2019). With regard to immigrants' labour market integration, the (2012) share of third country nationals who are not in education, employment or training (share of NEET) was the lowest in Denmark (25.2\%) 
followed by Germany (31.7\%) and much higher in France (44.7\%) (MIPEX 2014). Crossnational differences in policies aiming at improving immigrants' labour market integration point to a similar country ranking: targeted support for immigrants' labour market integration is similarly high in Germany and Denmark (90 points out of 100 on the MIPEX targeted support indicator) and much lower in France (50 points) (MIPEX 2014). Thus and in contrast to Denmark and Germany, France is characterised by a higher level of economic power among women and at the same time by a weaker labour market integration of its immigrant population and fewer targeted policies to support immigrants' labour market integration.

In each country, a sample of 3,000 respondents representative of the national working population in terms of age and gender took part in our survey experiment. The share of respondents with a leadership role was 36.2 percent of respondents $(N=1,103)$ in France, 33.0 percent of respondents $(\mathrm{N}=962)$ in Germany, and 21.4 percent of respondents $(\mathrm{N}=650)$ in Denmark. The final sample includes 4,264 respondents with answers for 4 vignettes each, summing up to 17,056 units. Of the 9,088 participants in the survey, 4,115 had to be deleted due to missing values on one of the included variables (listwise exclusion). Furthermore, all 709 respondents with an immigrant background (defined as persons without a citizenship status in the respective country and/or with at least one foreign-born parent) were removed from the sample. As the collected data do not contain any information on the country of origin, we cannot distinguish respondents from various European and non-European origin countries. Therefore, composition heterogeneity of this category hampers any meaningful interpretation. 
After having answered the four vignettes, respondents were asked to give their opinion on several attitudinal items. We measured women and ethnic prejudice with a set of four items. The first two items refer to prejudice against women: "Women don't have the necessary competencies and qualifications for leading positions"; "Women are less willing than men to fight for their careers". Next, ethnic prejudice was measured with the following items: "Is immigration to [country] good or bad for [the country's] economy?"; "Do immigrants undermine or enrich [country's] cultural life?". These attitudinal items could be answered on an 11-point Likert scale. We built two additive index measuring prejudice against women and ethnic prejudice ranging from 0 to 10 . Next, perceived unequal treatment faced by women and ethnic minorities was measured with the following items: (1) "Do you think that women are disadvantaged in hiring processes for leading positions in [country]?" and (2) "Do you think that persons with an immigration background are disadvantaged in hiring processes for leading positions in [country]?". These items could be answered with a fivepoint Likert scale ranging from "not disadvantaged at all" to "strongly disadvantaged". Lastly, acceptance of state intervention in the economy was measured with the following bipolar 11-point Likert scale item: “Individuals should take more responsibility for providing for themselves" vs "The state should take more responsibility to ensure that everyone is provided for". All attitudinal variables were centred on their mean. In the regression analyses, we control for a set of socio-demographic characteristics that have shown to be associated with support for a gender quota (Möhring, Teney, and Buss 2019; Möhring and Teney 2020; Barnes and Córdova 2016): gender, age, cohabitation status, educational attainment (in three categories), personal income (in three categories) and holding a leadership position. Moreover, we controlled for respondents' sector of activity (working in 
the public/ non-profit sector vs in the profit sector) and respondents' number of children. Appendix Table A.1 presents the descriptive statistics and the average level of perceived discrimination of women and immigrants, of prejudice against women and immigrants and of opinion toward state intervention in Germany, France, and Denmark.

\section{Estimation strategy}

The units of analysis are the vignettes (with respondents' evaluation of the vignette as a dependent variable). We have thus a within-subject experimental design as each respondent evaluated four vignettes. We use a two-level random slope model to analyse variations in the support for AAP along target groups (Auspurg and Hinz 2015). Vignettes (level 1) are clustered within respondents (level 2). The target group dimension (measured at the vignette level, level 1) is allowed to vary across respondents (level 2). Moreover, we include in each model a cross-level interaction between respondents' gender and the target group dimension. We introduce country dummy (with Germany as reference category) in the models and interact them with gender and with the target group dimension of the vignette (three-ways interactions). In each model we control for the order of the vignettes with a dummy variable coded 0 for the first and 1 for the second to fourth vignette.

\section{Results}

We structure our results in two parts. First, we focus our analyses on target group differences in support for AAP. Then, we turn to the analyses aiming to assess the factors behind country differences in the overall support for AAP. 


\section{Target Group Differences in Support for AAP}

For assessing our hypotheses on target group differences in support for AAP, we conduct four multilevel regression models (see Models 1-4 of Appendix Table A.2). The main model is composed of the vignettes' target groups, respondents' gender, the country dummies and the control variables. In addition, the main model contains (cross-level) interaction terms of the AAP target group with gender and countries. In the second model, we add our measures of ethnic and gender prejudice. Model 3 is constituted of the main model variables and of our items on perceived disadvantage of women and immigrants on the labour market. Finally, Model 4 contains the variables of the main model, the two prejudice measures and the two perceived disadvantage items.

Figure 2 plots the predicted values of support for AAP for each target group by respondents' gender (see Main Model of Appendix Table A.2 for the corresponding multilevel regression coefficients). The results presented in Figure 2 enable us to test and confirm our hypotheses $1 \mathrm{a}$ and $1 \mathrm{~b}$. Recall that these hypotheses are derived from the identity deserving criterion and aim to explain (respondents') gender differences in support for AAP. The predicted values in Figure 2 show indeed that women support AAP for women and immigrants to a significantly larger extent than men support AAP for women (Hypothesis 1a) and for immigrants (Hypothesis 1b, with the exception of German women). The respondents' gender gap is however larger for AAP for women than for AAP for immigrants. That is, women do support AAP for their own group to a larger extent than AAP for immigrants. Thus, our results confirm: first, the group-based interest explanation (i.e., that women support AAP for their own group to a larger extent); and second, the fact that members of an 
underrepresented group (in this case women) tend to support AAP for other underrepresented groups to a larger extent than members of the majority.

Figure 2: Predicted Values of Support for a Quota in Recruitment Processes for Women and Immigrants, by Respondents' Gender
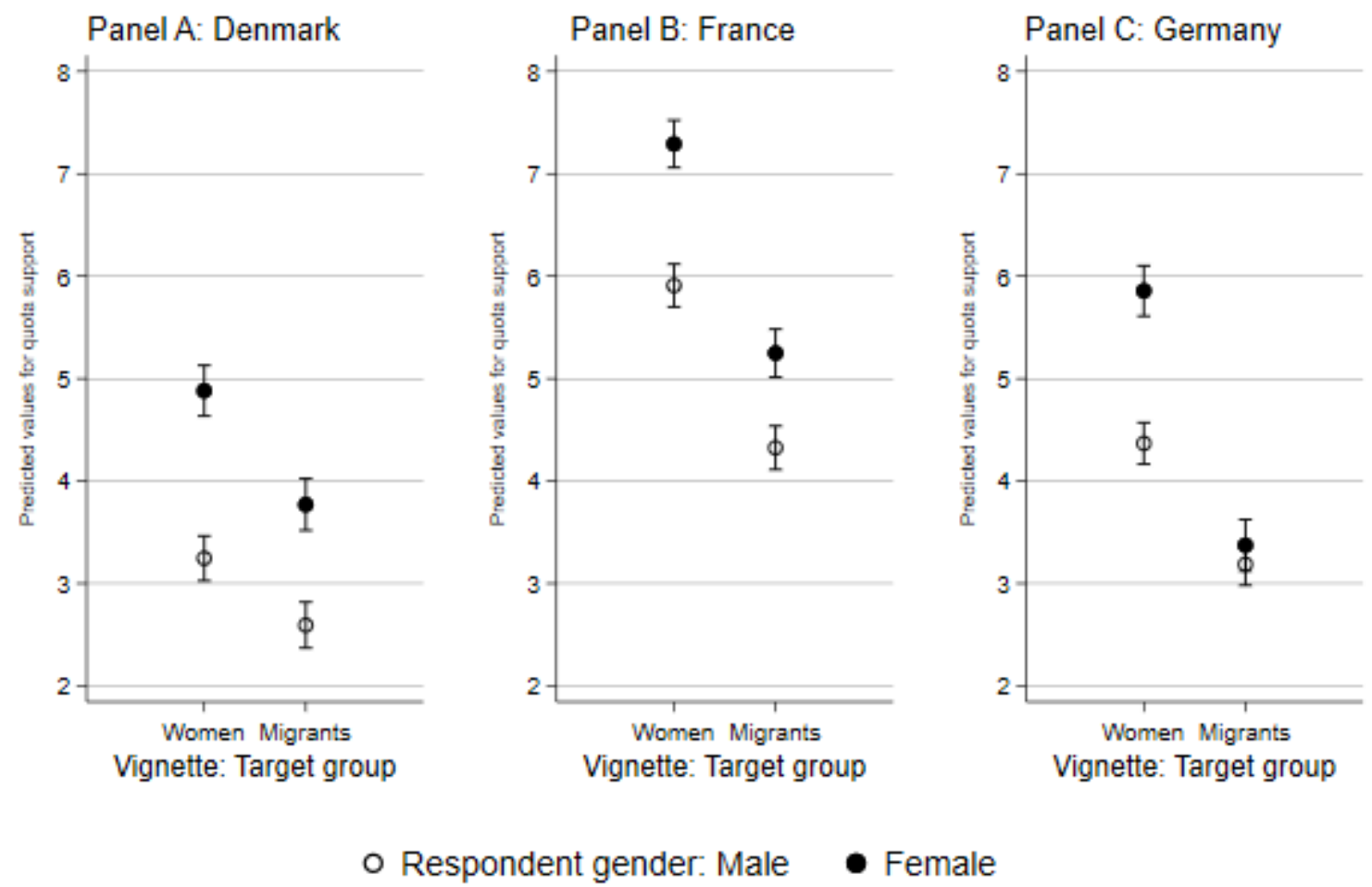

Note: Controlling for sector of activity, holding a managing position, income, education, age, marital status, number of children, and vignette order

Next, Figure 3 presents the coefficients (1) of gender and ethnic prejudice (Panels A and C) and (2) of perceived disadvantage of women and immigrants (Panels B and D) on support for AAP for both target groups. The corresponding multilevel regressions coefficients can be found in Model 2 (for prejudice) and Model 3 (for perceived disadvantage) of Appendix Table A.2. Both measures of prejudice are significantly and negatively associated with support for 
AAP for the corresponding target group. Moreover, and interestingly, they are correlated significantly with support for AAP for the other target group (see Model 2 in Appendix Table A.2). Respondents with a high level of ethnic prejudice will be significantly less likely to support AAP for women. By contrast, respondents with a high level of prejudice against women are significantly more likely to support AAP for immigrants. The predicted values of support for AAP for both target groups for respondents with a high level of prejudice against women need however to be interpreted with caution: very few respondents hold high level of prejudice against women, which explains the particularly large confidence intervals on the right-hand side of the Graph on prejudice against women. More importantly for the assessment of our second hypothesis, both prejudice measures can explain the target group gap in support for AAP. Thus, the fact that respondents support AAP for women to a much larger extent than AAP for immigrants is due to differences in the overall level of ethnic and gender prejudice. Respondents with a low level of ethnic prejudice and respondents with a high level of gender prejudice hold similar level of support for AAP regardless the AAP's target group. These results confirm our second hypothesis: the fact that AAP for women receives more support than AAP for immigrants is due to varying levels of prejudice against immigrants and women. Thus, the attribute criterion of deservingness can also help explain differences in level of support for AAP for different target groups. 
Figure 3: Predicted Values of Support for a Quota in Recruitment Processes for Women and Immigrants, Effect of Prejudice and Perceived Disadvantage, by Vignette Target Group
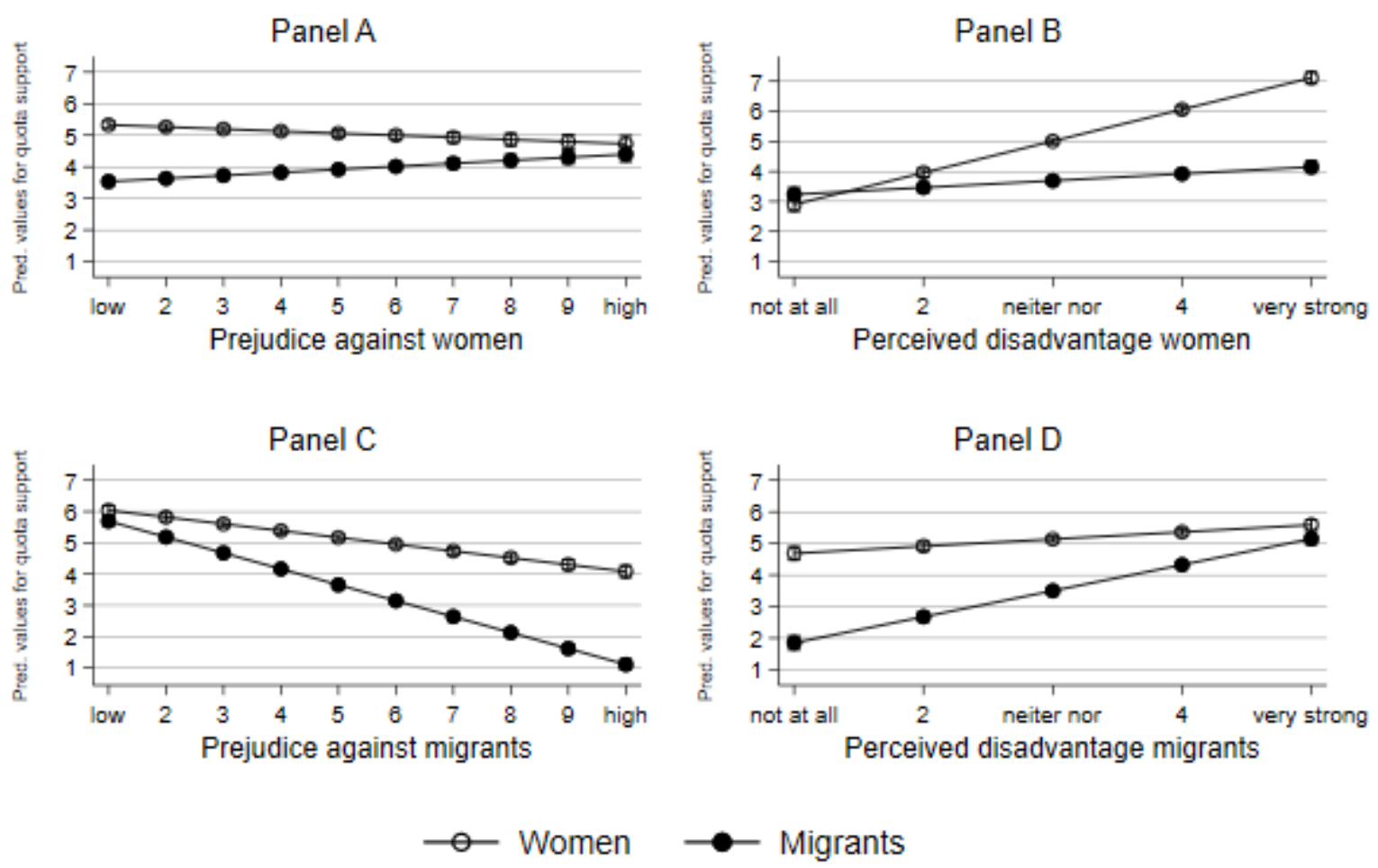

Note: Controlling for gender, sector of activity, holding a managing position, income, education, age, marital status, number of children, countries, and vignette order

Panel B and D of Figure 3 present the effects of perceived disadvantage of women and immigrants on support for AAP for both target groups (see Model 3 in Appendix Table A.2 for the corresponding multilevel regression coefficients). Here again we can see that both variables can explain the target group gap in support for AAP. First, respondents who perceive immigrants as strongly disadvantaged on the labour market support AAP for persons of immigrant origin to the same extent as they support AAP for women. Second, the level of support for AAP for women is as low as the level of support for AAP for immigrants 
among respondents who think that women don't face any disadvantage on the labour market. These results confirm our third hypothesis: target group differences in support for AAP are also due to varying levels of perceived disadvantage of women and immigrants on the labour market. This also points to the relevance of the control criterion for explaining target group differences in support for AAP: members of underrepresented groups who are perceived to have little or no personal control for getting in or out of their situation are judged as more deserving of AAP. For the sake of comprehensiveness, we provide the multilevel regression results combining the two prejudice measures and the two perceived disadvantage items (see Model 4 in Appendix Table A.2).

\section{Country Differences in Support for AAP}

Turning now to the second part of our analysis, we focus on country differences in the overall support for AAP for women and persons of immigrant origin. Recall that we hypothesise that the country differences in support for AAP can be explained by country differences in the overall level (1) of ethnic and gender prejudice and of perceived disadvantage faced by women and immigrants (Hypothesis 4) and (2) of support for state intervention in the economy (Hypothesis 5). Figure 4 presents the results for the country differences in support for AAP Panel A (for the regression coefficients, see Model 1 in Appendix Table A.2) corresponds to our main model with a dummy for the vignette target group (and interaction terms of target group vignette with gender and the country dummies), a dummy for gender, country dummies and our set of socio-demographic control variables. Accordingly, French respondents are much more likely than German and Danish respondents to support AAP toward both target groups. Moreover, Danes are significantly less likely than Germans to 
support AAP for women, but share a similar level of support of AAP for immigrants. Thus, we find significant country differences in the overall support for AAP, with the exception of Germans and Danes' support of AAP for immigrants.

Figure 4: Predicted Values of Support for a Quota in Recruitment Processes for Women and Immigrants, by Country
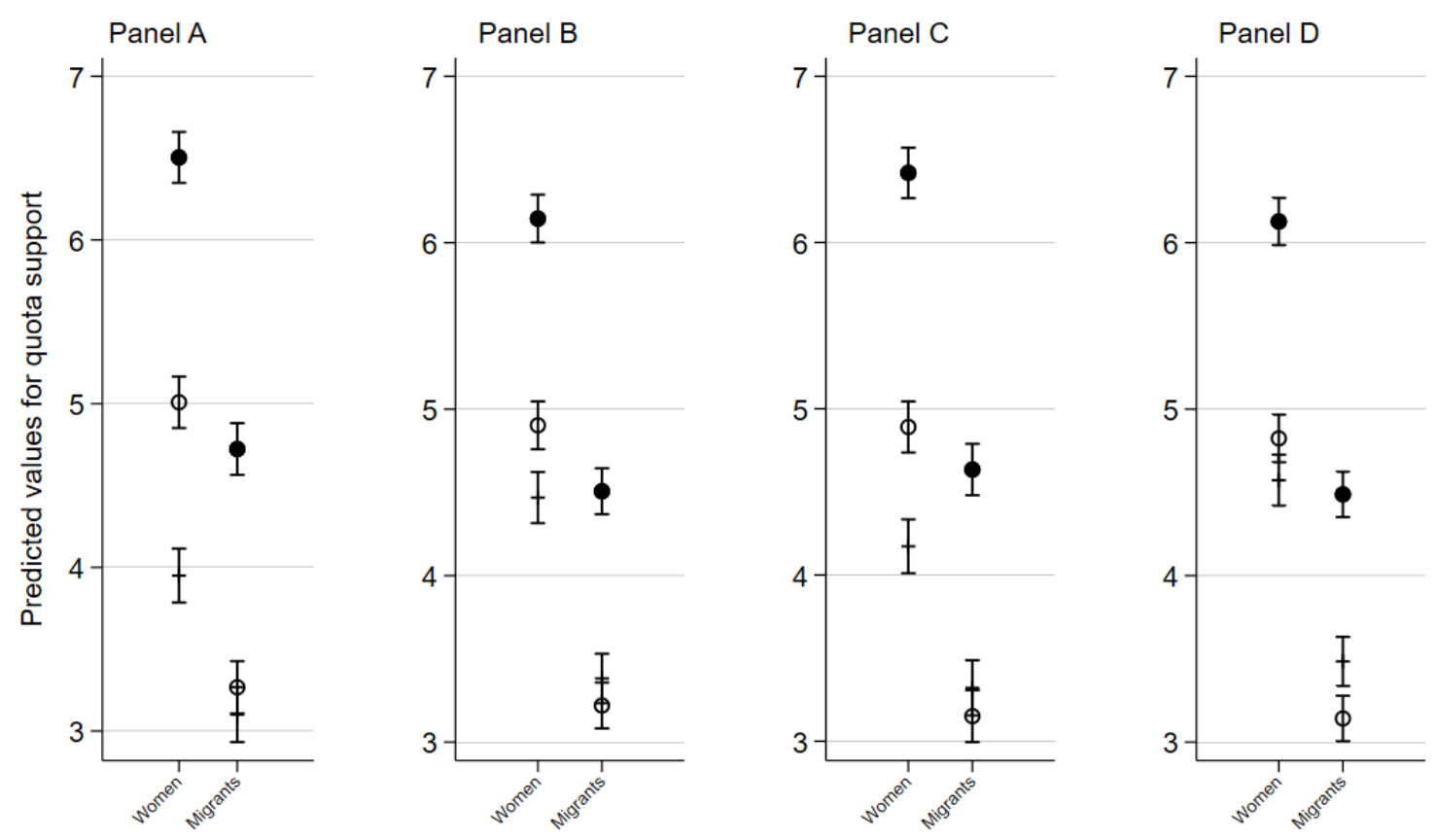

Vignette: target group

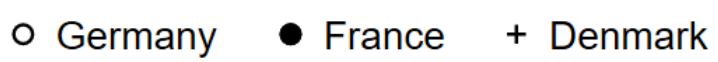

Note: Panel A: Main model

Panel B: controlling for prejudice against and perceived disadvantage of women and migrants (see Model 4 in Appendix Table A.2)

Panel C: controlling for support of state intervention (see Model 5 in Appendix Table A.2)

Panel D: controlling for against, perceived disadvantage of women and migrants, and support of state intervention (see Model 6 in Appendix Table A.2) 
In Panel B of Figure 4 (see Model 5 in Appendix Table A.2 for the corresponding regression coefficients), we introduce our measures of prejudice against immigrants and women and perceived disadvantage of women and of immigrants. As can be seen, controlling for this set of attitudinal variables can explain a large portion of the gap between Germany and Denmark in support of AAP for women. However, these attitudinal variables only slightly help reduce the gap between the French respondents and the German and Danish respondents in their support for AAP for both target groups. These findings provide some support for our fourth hypothesis: country differences (at least differences between Germany and Denmark in support for AAP for women) are due to different levels of ethnic and gender prejudice and of perceived disadvantage of the AAP target groups.

In Panel C of Figure 4 (see Model 6 in Appendix Table A.2 for the regression coefficients), we introduce our measure of support for state intervention. As can be seen, including a variable on attitudes toward state intervention in the economy can explain some of the differences between Denmark and Germany in the overall support of APP for women. By contrast, the predicted values for France remain stable once we control for attitudes toward state intervention. Thus, and here again, the fact that French respondents show much larger support for AAP for both target groups than Germans is not due to different national levels of support for state intervention. Hence, our results partly confirm our fifth hypothesis, but only for German-Danish differences. Finally, Panel D (see Model 6 in Appendix Table A.2 for the corresponding regression coefficients) combines the measures of prejudice, perceived disadvantage and support for state intervention. Here again, we see that the German and Danish respondents hold similar level of support for AAP, while the French respondents 
support to a significantly larger extent AAP for both target groups, when controlling for our set of attitudinal variables.

\section{Conclusion}

The implementation of AAP for redressing inequality has been vividly discussed in the public debate of most Western democracies. The lack of empirical studies on support for and opposition to AAP outside of the US context is therefore striking. With this contribution, we want to highlight both the scientific and societal relevance of conducting comparative studies on this issue. Based on a unique international factorial experiment survey, our study enabled us to compare the support for AAP for two different target groups (i.e., women and persons of immigrant origin) in three different countries (i.e., Germany, France and Denmark). Our results show that members of underrepresented groups support AAP for both their own group and for other underrepresented groups to a larger extent than members of the majority group. Thus, a group-interest based explanation is not sufficient to explain group differences in support for AAP. Indeed, our results point to the fact that members of an underrepresented group seem to perceive more solidarity toward members of other underrepresented groups and identify more largely with them than members of the majority. This, in turn, confirms the findings of previous (US) studies (e.g., Scarborough, Lambouths, and Holbrook 2019). Unfortunately, our sample design did not enable us to investigate support for AAP among respondents from underrepresented groups other than

women. Future studies encompassing larger samples of respondents of underrepresented 
groups would be able to assess the generalisability of our finding to members of other underrepresented groups in cross-national perspective.

Moreover, our results show that target group differences in support for AAP are mainly due to varying levels of prejudice against the AAP target groups and of perceived disadvantage of target group members on the labour market. Investigating the generalisability of our findings to other potential AAP target groups would constitute another important future research avenue. Lastly, we could show that the differences between Danes and Germans in their level of support for AAP for women can be entirely accounted for by differences in national levels of ethnic and gender prejudice, of perceived disadvantage of women and immigrants and of attitudes toward state intervention. All in all, prejudice against target groups and perceived structural disadvantage of target group members seem to play a particularly important role in both target group and country differences in support for AAP. Strikingly, however, neither these variables nor attitudes toward state intervention in the economy were able to explain why our French respondents show such a high level of support for AAP for both target groups. Providing further potential explanations for these French particularities would be highly speculative at this stage and goes beyond the main purpose of our article.

Turning now to the theoretical contribution of our paper, we showed the relevance of translating the deservingness theory for welfare program and redistributive solidarity (van Oorschot 2000) to the case of AAP. Three out of the five deservingness criteria (i.e., identity, attitudes and control) turned out to be powerful explanatory factors for target group and country differences in support for AAP. We want nevertheless to mention one main 
limitation of the deservingness theory for analysing support for AAP for different target groups. We operationalised the control criterion of deservingness with an item of perceived disadvantage of women and immigrants on the labour market. The items we used only focus on the perception of disadvantage without measuring the causes for this perceived disadvantage faced by target group members. However, the reasons for the underrepresentation of women and of persons of immigrant origin in managing positions are hardly comparable. The underrepresentation of women in managing positions in our selected countries results mostly from the particular challenges faced by women when combining family and career. By contrast, the underrepresentation of immigrants in managing positions in France, Germany and Denmark is mainly due to the lower propensity of immigrants to hold the education credentials required for such managing positions. A more fine-grained assessment of the role of the control deserving criterion in support for AAP would require measures not only of the perception of disadvantage faced by the target groups but also of the perceived causes of this disadvantage. 


\section{References}

Auspurg, Katrin, and Thomas Hinz. 2015. Factorial Survey Experiments. Los Angeles: Sage.

Barnes, Tiffany D., and Abby Córdova. 2016. “Making Space for Women: Explaining Citizen Support for Legislative Gender Quotas in Latin America." The Journal of Politics 78 (3): 670-86. https://doi.org/10.1086/685379.

Bay, Ann-Helén, and Axel West Pedersen. 2006. “The Limits of Social Solidarity: Basic Income, Immigration and the Legitimacy of the Universal Welfare State". Acta Sociologica 49(4):419-36. https://doi.org/10.1177/0001699306071682.

Bobo, Lawrence D. 2000. "Race and Beliefs about Affirmative Action: Assessing the Effects of Interests, Group Threat, Ideology and Racism." In Racialized Politics: The Debate about Racism in America, edited by D. O. Sears, J. Sidanius, and L. Bobo, 137-64. Chicago: University Chicago Press.

Bolzendahl, Catherine, and Hilde Coffé. 2020. "Public Support for Increasing Women and Minority MPs." Politics \& Gender 16 (3): 681-710. https://doi.org/10.1017/S1743923X19000217.

Dämmrich, Johanna, and Hans-Peter Blossfeld. 2017. “Women's Disadvantage in Holding Supervisory Positions. Variations among European Countries and the Role of Horizontal Gender Segregation". Acta Sociologica 60(3):262-82. https://doi.org/10.1177/0001699316675022.

de Zwart, Frank. 2000. "The Logic of Affirmative Action: Caste, Class and Quotas in India”. Acta Sociologica 43(3):235-49. https://doi.org/10.1177/000169930004300304. 
Dixon, John, Kevin Durrheim, and Manuela Thomae. 2017. “The Principle-Implementation Gap in Attitudes Towards Racial Equality (and How to Close It)." Political Psychology 38 (S1): 91-126. https://doi.org/10.1111/pops.12393.

EIGE. 2019. Gender Equality Index. Brussels: EIGE.

https://eige.europa.eu/publications/gender-equality-index-2019-work-lifebalance.

Feather, N. T. 1999. "Judgments of Deservingness: Studies in the Psychology of Justice and Achievement." Personality and Social Psychology Review 3 (2): 86-107. https://doi.org/10.1207/s15327957pspr0302_1.

Fukuyama, Francis. 2018. Identity. The Demand for Dignity and the Politics of Resentment. New York: Farrar, Straus and Giroux.

Harell, Allison, Stuart Soroka, and Shanto Iyengar. 2016. "Race, Prejudice and Attitudes toward Redistribution: A Comparative Experimental Approach." European Journal of Political Research 55 (4): 723-44. https://doi.org/10.1111/1475-6765.12158.

Harrison, David A., David A. Kravitz, David M. Mayer, Lisa M. Leslie, and Dalit Lev-Arey. 2006. "Understanding Attitudes Toward Affirmative Action Programs in Employment: Summary and Meta-Analysis of 35 Years of Research." Journal of Applied Psychology 91 (5): 1013-36.

Kane, Emily W., and Kimberly J. Whipkey. 2009. “Predictors of Public Support for GenderRelated Affirmative Action: Interests, Gender Attitudes, and Stratification Beliefs." Public Opinion Quarterly 73 (2): 233-54. https://doi.org/10.1093/poq/nfp019. King, Russell. 2002. “Towards a New Map of European Migration." International Journal of Population Geography 8 (2): 89-106. https://doi.org/10.1002/ijpg.246. 
Koopmans, Ruud. 2013. "Multiculturalism and Immigration: A Contested Field in CrossNational Comparison." Annual Review of Sociology.

Kootstra, Anouk. 2016. “Deserving and Undeserving Welfare Claimants in Britain and the Netherlands: Examining the Role of Ethnicity and Migration Status Using a Vignette Experiment." European Sociological Review 32 (3): 325-38. https://doi.org/10.1093/esr/jcw010.

Krysan, Maria. 2000. "Prejudice, Politics, and Public Opinion: Understanding the Sources of Racial Policy Attitudes." Annual Review of Sociology 26: 135-68.

Laenen, Tijs, Federica Rossetti, and Wim van Oorschot. 2019. "Why Deservingness Theory Needs Qualitative Research: Comparing Focus Group Discussions on Social Welfare in Three Welfare Regimes." International Journal of Comparative Sociology 60 (3): 190-216. https://doi.org/10.1177/0020715219837745.

MIPEX. 2014. Migrant Integration Policy Index. Brussels. https://www.mipex.eu/downloadpdf.

Möhring, Katja, and Cèline Teney. 2020. “Equality Prescribed? Contextual Determinants of Citizens' Support for Gender Boardroom Quotas across Europe." Comparative European Politics 18 (4): 560-89. https://doi.org/10.1057/s41295-019-00199-w. Möhring, Katja, Cèline Teney, and Christopher Buss. 2019. “Who Supports Gender Quotas for Company Leadership? An Empirical Analysis of Determinants of Support and Rejection among German Citizens." Soziale Welt 70: 121-43.

Oorschot, Wim van. 2000. "Who Should Get What, and Why? On Deservingness Criteria and the Conditionality of Solidarity among the Public." Policy \& Politics 28 (1): 33-48. https://doi.org/10.1332/0305573002500811. 
——_. 2006. "Making the Difference in Social Europe: Deservingness Perceptions among Citizens of European Welfare States." Journal of European Social Policy 16 (1): 2342. https://doi.org/10.1177/0958928706059829.

__—. 2008. "Solidarity towards Immigrants in European Welfare States." International Journal of Social Welfare 17 (1): 3-14. https://doi.org/10.1111/j.14682397.2007.00487.x.

Pew Research Center. 2018. Western Europe: People Favor Political Parties Based on Ideological Beliefs. https://www.pewresearch.org/global/2018/07/12/in-westerneurope-populist-parties-tap-anti-establishment-frustration-but-have-little-appealacross-ideological-divide/.

Reeskens, Tim, and Tom van der Meer. 2019. “The Inevitable Deservingness Gap: A Study into the Insurmountable Immigrant Penalty in Perceived Welfare Deservingness." Journal of European Social Policy 29 (2): 166-81. https://doi.org/10.1177/0958928718768335.

Scarborough, William J., Danny L. Lambouths, and Allyson L. Holbrook. 2019. “Support of Workplace Diversity Policies: The Role of Race, Gender, and Beliefs about Inequality." Social Science Research 79 (March): 194-210. https://doi.org/10.1016/j.ssresearch.2019.01.002.

Smith, Ryan A., and Matthew 0. Hunt. 2020. „White Supervisor and Subordinate Beliefs about Black/White Inequality: Implications for Understanding and Reducing Workplace Racial Disparities“. Social Problems (spaa014). doi: 10.1093/socpro/spaa014. 
Sniderman, Paul, Gretchen Crosby, and William Howell. 1999. “The Politics of Race.” In , 236-79. 


\section{Appendix}

Table A.1

\begin{tabular}{|c|c|c|c|c|c|c|c|c|c|c|}
\hline \multirow{2}{*}{ Variable } & \multicolumn{3}{|c|}{ All countries } & \multicolumn{2}{|c|}{ Denmark } & \multicolumn{3}{|c|}{ France } & \multicolumn{2}{|c|}{ Germany } \\
\hline & Min & Max & Mean & Std. Dev. & Mean & Std. Dev. & Mean & Std. Dev. & Mean & Std. Dev. \\
\hline Quota support & 0 & 10 & 4.54 & 3.34 & 3.53 & 3.06 & 5.82 & 3.14 & 4.17 & 3.37 \\
\hline Prejudice against women & 0 & 10 & 2.97 & 2.64 & 3.09 & 2.42 & 2.48 & 2.72 & 3.36 & 2.67 \\
\hline Prejudice against immigrants & 0 & 10 & 4.87 & 2.84 & 5.04 & 2.78 & 4.68 & 2.86 & 4.90 & 2.87 \\
\hline Perceived disadvantage women & 1 & 5 & 3.18 & 1.08 & 2.75 & 1.06 & 3.49 & 0.97 & 3.27 & 1.07 \\
\hline Perceived disadvantage immigrants & 1 & 5 & 3.28 & 1.11 & 3.11 & 1.10 & 3.48 & 1.09 & 3.24 & 1.11 \\
\hline Support of state intervention & 0 & 10 & 4.87 & 2.20 & 4.13 & 2.14 & 5.16 & 2.21 & 5.25 & 2.06 \\
\hline Gender: Female & 0 & 1 & 0.43 & 0.50 & 0.44 & 0.50 & 0.45 & 0.50 & 0.40 & 0.49 \\
\hline \multicolumn{11}{|l|}{ Work sector } \\
\hline Private & 0 & 1 & 0.62 & 0.48 & 0.57 & 0.50 & 0.61 & 0.49 & 0.69 & 0.46 \\
\hline Public/Non-Profit & 0 & 1 & 0.38 & 0.48 & 0.43 & 0.50 & 0.39 & 0.49 & 0.31 & 0.46 \\
\hline \multicolumn{11}{|l|}{ Work position } \\
\hline No leadership position & 0 & 1 & 0.65 & 0.48 & 0.75 & 0.43 & 0.60 & 0.49 & 0.63 & 0.48 \\
\hline Leadership position & 0 & 1 & 0.35 & 0.48 & 0.25 & 0.43 & 0.40 & 0.49 & 0.37 & 0.48 \\
\hline \multicolumn{11}{|l|}{ Personal income } \\
\hline low & 0 & 1 & 0.27 & 0.44 & 0.21 & 0.41 & 0.32 & 0.47 & 0.27 & 0.45 \\
\hline medium & 0 & 1 & 0.49 & 0.50 & 0.46 & 0.50 & 0.45 & 0.50 & 0.54 & 0.50 \\
\hline high & 0 & 1 & 0.25 & 0.43 & 0.33 & 0.47 & 0.23 & 0.42 & 0.18 & 0.39 \\
\hline \multicolumn{11}{|l|}{ Educational attainment } \\
\hline low & 0 & 1 & 0.15 & 0.35 & 0.07 & 0.26 & 0.27 & 0.44 & 0.09 & 0.28 \\
\hline medium & 0 & 1 & 0.23 & 0.42 & 0.20 & 0.40 & 0.14 & 0.34 & 0.35 & 0.48 \\
\hline high & 0 & 1 & 0.63 & 0.48 & 0.73 & 0.45 & 0.60 & 0.49 & 0.57 & 0.50 \\
\hline Age & 18 & 86 & 43.86 & 12.10 & 46.05 & 12.56 & 41.92 & 11.34 & 43.84 & 12.09 \\
\hline Lives with partner & 0 & 1 & 0.69 & 0.46 & 0.70 & 0.46 & 0.76 & 0.43 & 0.60 & 0.49 \\
\hline Has child(ren) & 0 & 1 & 0.60 & 0.49 & 0.69 & 0.46 & 0.65 & 0.48 & 0.47 & 0.50 \\
\hline
\end{tabular}

Source: Own calculations using YouGov Survey, September 2018 
Table A.2. Multilevel regression models of support for a quota in recruitment processes, vignette experiments

\begin{tabular}{|c|c|c|c|c|c|c|}
\hline & $\begin{array}{c}(1) \\
\text { Main }\end{array}$ & $\begin{array}{c}(2) \\
\text { Prejudice }\end{array}$ & $\begin{array}{c}\text { (3) } \\
\text { Perceived } \\
\text { disadvantage }\end{array}$ & $\begin{array}{c}\text { (4) } \\
\text { Prejudice, } \\
\text { disadvantage }\end{array}$ & $\begin{array}{c}\text { (5) } \\
\text { State } \\
\text { intervention }\end{array}$ & $\begin{array}{c}(6) \\
\text { Prejudice, } \\
\text { disadvantage, } \\
\text { state interv. }\end{array}$ \\
\hline Respondent: Female & $\begin{array}{l}1.498^{* * *} \\
(0.163)\end{array}$ & $\begin{array}{l}1.497^{* * *} \\
(0.159)\end{array}$ & $\begin{array}{l}0.848^{* * *} \\
(0.152)\end{array}$ & $\begin{array}{l}0.920^{* * *} \\
(0.150)\end{array}$ & $\begin{array}{l}1.418^{* * *} \\
(0.158)\end{array}$ & $\begin{array}{l}0.920^{* * *} \\
(0.148)\end{array}$ \\
\hline Vignette: Migrant & $\begin{array}{c}-1.178^{* * *} \\
(0.089)\end{array}$ & $\begin{array}{l}-1.381^{* * *} \\
(0.084)\end{array}$ & $\begin{array}{c}-1.249^{* * *} \\
(0.085)\end{array}$ & $\begin{array}{c}-1.431^{* * *} \\
(0.081)\end{array}$ & $\begin{array}{c}-1.178^{* * *} \\
(0.089)\end{array}$ & $\begin{array}{c}-1.431^{* * *} \\
(0.081)\end{array}$ \\
\hline Resp.: Female \# Vign.: Migrant & $\begin{array}{c}-1.307^{* * *} \\
(0.141)\end{array}$ & $\begin{array}{c}-1.008^{* * *} \\
(0.132)\end{array}$ & $\begin{array}{c}-0.897^{* * *} \\
(0.136)\end{array}$ & $\begin{array}{c}-0.671^{* * *} \\
(0.129)\end{array}$ & $\begin{array}{c}-1.303^{* * *} \\
(0.141)\end{array}$ & $\begin{array}{c}-0.669^{* * *} \\
(0.129)\end{array}$ \\
\hline Country (Ref.: Germany) & & & & & & \\
\hline France & $\begin{array}{l}1.521^{* * *} \\
(0.150)\end{array}$ & $\begin{array}{l}1.451^{* * *} \\
(0.146)\end{array}$ & $\begin{array}{l}1.188^{* * *} \\
(0.138)\end{array}$ & $\begin{array}{l}1.248^{* * *} \\
(0.137)\end{array}$ & $\begin{array}{l}1.539^{* * *} \\
(0.146)\end{array}$ & $\begin{array}{l}1.299^{* * *} \\
(0.135)\end{array}$ \\
\hline Denmark & $\begin{array}{c}-1.124^{* * *} \\
(0.154)\end{array}$ & $\begin{array}{c}-0.997^{* * *} \\
(0.150)\end{array}$ & $\begin{array}{l}-0.379^{* *} \\
(0.144)\end{array}$ & $\begin{array}{l}-0.303^{*} \\
(0.143)\end{array}$ & $\begin{array}{c}-0.736^{* * *} \\
(0.151)\end{array}$ & $\begin{array}{c}-0.106 \\
(0.142)\end{array}$ \\
\hline Resp.: Female*France & $\begin{array}{c}-0.115 \\
(0.224)\end{array}$ & $\begin{array}{c}-0.164 \\
(0.218)\end{array}$ & $\begin{array}{c}0.042 \\
(0.206)\end{array}$ & $\begin{array}{c}0.011 \\
(0.204)\end{array}$ & $\begin{array}{c}-0.073 \\
(0.218)\end{array}$ & $\begin{array}{c}0.031 \\
(0.201)\end{array}$ \\
\hline Resp.: Female*Denmark & $\begin{array}{c}0.128 \\
(0.231)\end{array}$ & $\begin{array}{c}-0.085 \\
(0.226)\end{array}$ & $\begin{array}{c}-0.195 \\
(0.214)\end{array}$ & $\begin{array}{c}-0.285 \\
(0.211)\end{array}$ & $\begin{array}{c}0.022 \\
(0.225)\end{array}$ & $\begin{array}{l}-0.318 \\
(0.209)\end{array}$ \\
\hline Vign.: Migrant*France & $\begin{array}{l}-0.405^{* *} \\
(0.128)\end{array}$ & $\begin{array}{l}-0.275^{*} \\
(0.120)\end{array}$ & $\begin{array}{l}-0.338^{* *} \\
(0.122)\end{array}$ & $\begin{array}{c}-0.207 \\
(0.116)\end{array}$ & $\begin{array}{l}-0.410^{* *} \\
(0.128)\end{array}$ & $\begin{array}{l}-0.209 \\
(0.116)\end{array}$ \\
\hline Vign.: Migrant*Denmark & $\begin{array}{l}0.527^{* * *} \\
(0.131)\end{array}$ & $\begin{array}{l}0.765^{* * *} \\
(0.122)\end{array}$ & $\begin{array}{c}0.215 \\
(0.127)\end{array}$ & $\begin{array}{c}0.383^{* *} \\
(0.120)\end{array}$ & $\begin{array}{l}0.525^{* * *} \\
(0.131)\end{array}$ & $\begin{array}{c}0.382^{* *} \\
(0.120)\end{array}$ \\
\hline Resp.: Female*Vign.: Migrant*France & $\begin{array}{l}0.847^{* * *} \\
(0.197)\end{array}$ & $\begin{array}{l}0.697^{* * *} \\
(0.183)\end{array}$ & $\begin{array}{l}0.693^{* * *} \\
(0.187)\end{array}$ & $\begin{array}{l}0.586^{* * *} \\
(0.177)\end{array}$ & $\begin{array}{l}0.847^{* * *} \\
(0.196)\end{array}$ & $\begin{array}{l}0.587^{* * *} \\
(0.177)\end{array}$ \\
\hline Resp.: Female*Vign.: Migrant*Denmark & $\begin{array}{l}0.846^{* * *} \\
(0.202)\end{array}$ & $\begin{array}{c}0.452^{*} \\
(0.189)\end{array}$ & $\begin{array}{l}0.733^{* * *} \\
(0.193)\end{array}$ & $\begin{array}{c}0.495^{* *} \\
(0.183)\end{array}$ & $\begin{array}{l}0.841^{* * *} \\
(0.202)\end{array}$ & $\begin{array}{c}0.492^{* *} \\
(0.182)\end{array}$ \\
\hline Prejudice against women ${ }^{1}$ & & $\begin{array}{c}-0.174^{* * *} \\
(0.045)\end{array}$ & & $\begin{array}{c}0.089^{*} \\
(0.043)\end{array}$ & & $\begin{array}{c}0.140^{* *} \\
(0.043)\end{array}$ \\
\hline Vign.: Migrant*prejudice against women ${ }^{1}$ & & $\begin{array}{l}0.424^{* * *} \\
(0.038)\end{array}$ & & $\begin{array}{l}0.289^{* * *} \\
(0.038)\end{array}$ & & $\begin{array}{l}0.291^{* * *} \\
(0.038)\end{array}$ \\
\hline Prejudice against immigrants ${ }^{1}$ & & $\begin{array}{c}-0.620^{* * *} \\
(0.046)\end{array}$ & & $\begin{array}{c}-0.451^{* * *} \\
(0.047)\end{array}$ & & $\begin{array}{c}-0.400^{* * *} \\
(0.047)\end{array}$ \\
\hline Vign.: Migrant*prejudice against immigrants ${ }^{1}$ & & $\begin{array}{c}-0.832^{* * *} \\
(0.038)\end{array}$ & & $\begin{array}{c}-0.791^{* * *} \\
(0.040)\end{array}$ & & $\begin{array}{c}-0.790^{* * *} \\
(0.040)\end{array}$ \\
\hline Perceived disadvantage women ${ }^{1}$ & & & $\begin{array}{l}1.131^{* * *} \\
(0.051)\end{array}$ & $\begin{array}{l}1.165^{* * *} \\
(0.052)\end{array}$ & & $\begin{array}{l}1.092^{* * *} \\
(0.052)\end{array}$ \\
\hline
\end{tabular}


Vign.: Migrant*Perceived disadvantage women ${ }^{1}$

Perceived disadvantage migrants ${ }^{1}$

Vign.: Migrant*Perceiv. disadvantage migrants ${ }^{1}$

Support of state intervention ${ }^{1}$

Job: public/nonprof. (Ref.: private sector)

Job: leadership position

Personal Income (Ref.: high)

low

medium

Educational attainment (Ref.: high)

low

medium

Age

Living with a partner (Ref.: no)

Has child(ren) (Ref.: no)

2.-4. vignette ( $R C$ : 1 . vignette)

$\begin{array}{lc}-0.887^{* * *} & -0.775^{* * *} \\ (0.046) & (0.045) \\ 0.250^{* * *} & 0.059 \\ (0.048) & (0.052) \\ 0.666^{* * *} & 0.319^{* * *} \\ (0.043) & (0.045)\end{array}$

0.157

(0.088)

0.125

(0.096)

$-0.219^{*}$

(0.104)

$-0.517^{* * *}$

(0.134)

$-0.370^{*}$

(0.146)

$-0.510^{* * *}$

(0.129)

$-0.008^{*}$

(0.004)

$-0.020$

(0.096)

$0.215^{*}$

(0.098)

$-0.109^{* * *}$

(0.017)

17056

4264

2401.951

$-3.31 e+04$

\subsection{8}

(0.081)

0.027

(0.088)

$-0.246^{*}$

(0.096)

$-0.624^{* * *}$

(0.123)

$0.213^{* *}$

(0.081)

$0.181^{*}$

(0.089)

$-0.195^{*}$

(0.096)

$-0.429^{* * *}$

(0.124)

$-0.360^{* *}$

$(0.135)$

$-0.561^{* * *}$

(0.119)

$-0.011^{* *}$

(0.004)

0.016

(0.089)

$0.234^{*}$

$(0.091)$
$-0.111^{* * *}$

(0.017)

$-0.106^{* * *}$

(0.017)

$\mathrm{N}$ respondents

4264

17056

4264

Log likelihood

$-3.25 e+04$

$-3.26 e+04$

(0.045)

0.080

(0.084)

$-0.216^{*}$

(0.091)

$-530^{*}$

$-0.312^{*}$

(0.128)

$-0.682^{* * *}$

$-0.008^{*}$

(0.003)

(0.084)

$0.267^{* *}$

(0.086)

$-0.109^{* * *}$

(0.017)

5138.923

$-3.22 \mathrm{e}+04$

$0.709^{* * *}$

$(0.042)$

0.042

(0.086)

0.115

(0.093)

$-0.069$

(0.101)

$-0.218$

(0.131)

$-0.774^{* * *}$

(0.045)

0.055

(0.051)

$0.318^{* * *}$

(0.045)

(0.039)

0.065

(0.077)

0.066

(0.083)

$-0.123$

(0.090)

$-0.344^{* *}$

(0.117)

$-0.346^{*}$

(0.141)

$-0.490^{* * *}$

$-0.303^{*}$

(0.125)

$-0.009^{*}$

(0.004)

$-0.011$

(0.093)

$0.234^{*}$

(0.095)

$-0.109^{* * *}$

(0.017)

$17056 \quad 17056$

4264

2739.990
$-3.30 \mathrm{e}+04$

$-0.655^{* * *}$

$(0.112)$

$-0.008^{*}$

(0.003)

0.059

(0.083)

$0.271^{* *}$

(0.085)

$-0.108^{* * *}$

(0.017)

4264

5348.516

Standard errors in parentheses; ${ }^{* * *} \mathrm{p}<0.001,{ }^{* *} \mathrm{p}<0.01,{ }^{*} \mathrm{p}<0.05$. Source: Own calculations using YouGov Survey, September 2018

1) Variables standardized 